\title{
Laparoscopic splenectomy in children with sickle cell disease younger than 5 years old
}

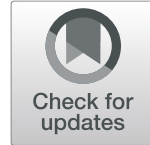

Taha Alkhatrawi ${ }^{* *}$, Radi Elsherbini ${ }^{2}$ and Waheed Turkistani ${ }^{1}$

\begin{abstract}
Background: The purpose of this paper is to evaluate the feasibility, safety, efficacy, benefits, and outcome of elective laparoscopic splenectomy for children younger than 5 years with sickle cell disease (SCD) who needed splenectomy. We conducted a retrospective review for a prospective data on patients younger than 5 years with SCD requiring splenectomy from January 2007 to June 2019. Patients were evaluated with regard to patient demographics, operative time, presence of accessory spleens, blood loss, length of hospital stay, morbidity, mortality, and clinical outcome.

Results: A total of 71 patients younger than 5 years with SCD underwent laparoscopic splenectomy (LS) at our institution from January 2007 to June 2019. There were 28 boys and 43 girls. The age at LS is from 2 years to less than 5 years (mean 3.2 years). The mean operating time was $65 \mathrm{~min}$. There was no conversion to open surgery; all the cases were successfully performed laparoscopically. Twelve patients (17\%) underwent a concomitant cholecystectomy. The hospital stay ranged from 2 to 6 days (median, 3 days). The mean follow-up was 86 months (range, 17 to 161 months). Postoperative follow-up revealed no cases of overwhelming postsplenectomy sepsis infection (OPSI).

Conclusion: Laparoscopic splenectomy in young children less than 5 years of age with sickle cell disease is a safe and effective treatment. When patients are given preoperative vaccination and penicillin prophylaxis, OPSI rarely occurs.
\end{abstract}

Keywords: Pediatric splenectomy, Laparoscopic splenectomy, Overwhelming postsplenectomy sepsis, Sickle cell disease

\section{Background}

Laparoscopic splenectomy (LS) for children was first described in 1993 and later gained wide acceptance among pediatric surgeons [1]. In hemolytic anemias in children, splenectomy was found to be useful to increase the circulating red cell mass in the circulation [2]. In order to treat or reduce the complications of SCD in children, such as anemia, splenic sequestration, vasoocclusive pain episodes, acute chest syndrome, and stroke, hematologist usually put these patients on regular packed red blood cell (PRBC) transfusions [3].

\footnotetext{
* Correspondence: tkhatrawi@gmail.com

'King Abdullah Medical City, Maternity and Children's Hospital, Madinah, Kingdom of Saudi Arabia

Full list of author information is available at the end of the article
}

\section{Methods}

Analysis and assessment of demographic data, indication for laparoscopic splenectomy (LS), number of splenic sequestration crisis, and occurrence of hypersplenism were done. Age at operation, concurrent procedures like cholecystectomy, and length of hospital stay were evaluated. Intraoperative and postoperative complications were reviewed. All of our patients had a preoperative ultrasound to check for the presence of gallstones as well as to measure the size of the spleen. All patients received preoperative vaccinations against Haemophilus influenzae, Neisseria meningitis, and Streptococcus pneumoniae. Postoperatively after LS, they all had antibiotic prophylaxis. Collection of hematologic data between 1 year preoperative and 1 year postoperative periods 
included the number of transfusion requirements and hemoglobin value.

\section{Technique}

We will briefly describe the technique of LS used for our patients. The patient is positioned with a $30^{\circ}$ tilt of the left side in a semilateral position. A small roll is placed under the right loin and the patient is fixed to the table. We use a 4-port technique: 1st at the lower edge of the umbilicus, 2nd in the midline between the umbilicus and xiphoid, 3rd in the midline below the xiphoid, and 4th at the left lower quadrant near the left inguinal region (to give enough space for the endocatch to open). Depending on the size of the patient's abdomen, we use either 5 or $3.5 \mathrm{~mm}$ ports. The ligasure is $5 \mathrm{~mm}$ or 10 $\mathrm{mm}$. The endobag used is either 15 or $10 \mathrm{~mm}$. The 1 st port is placed at the lower edge of the umbilicus by an open technique using an artery forceps to be introduced bluntly inside the peritoneal cavity. A $30^{\circ}$ telescope is introduced through the $5-\mathrm{mm}$ port to confirm the port is inside the peritoneum. Insufflation of the abdomen is a low flow to reach $12 \mathrm{mmHg}$. The remaining three ports are introduced by a closed technique. At the beginning of the procedure, a search is made for accessory spleens. If any accessory spleens are found, they are removed through the left lower quadrant port, which is replaced by an 11-mm port.

The splenocolic ligaments are identified and divided with ligasure. Division of the short gastric vessels by ligasure is starting from inferior to superior (Fig. 1). The last upper short gastric vessel should be divided with care to avoid bleeding and gastric injury. In our opinion, this is the most difficult part of the procedure. The splenic vessels are then divided by ligasure (Fig. 2). The remaining attachment of the spleen to the diaphragm is taken

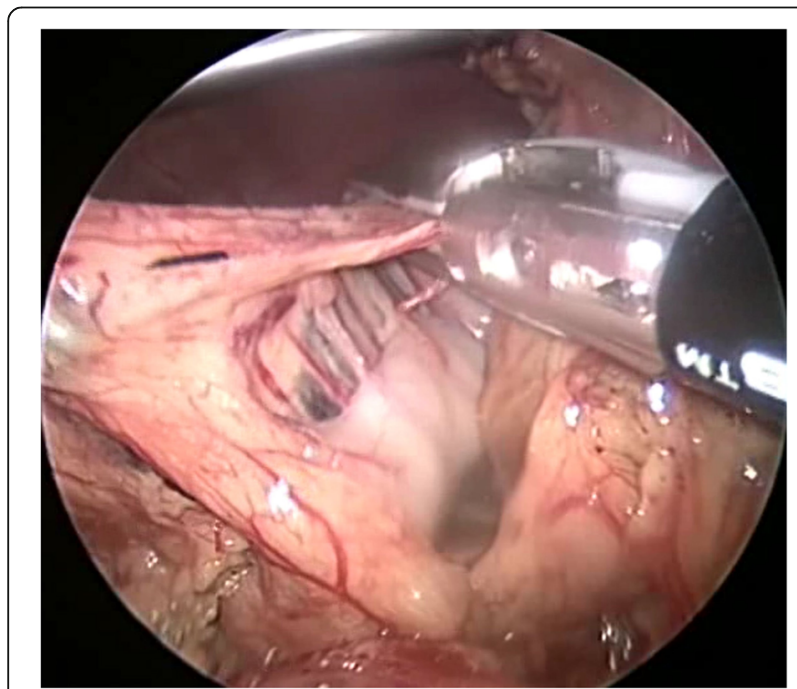

Fig. 1 Division of the short gastric vessels by ligasure

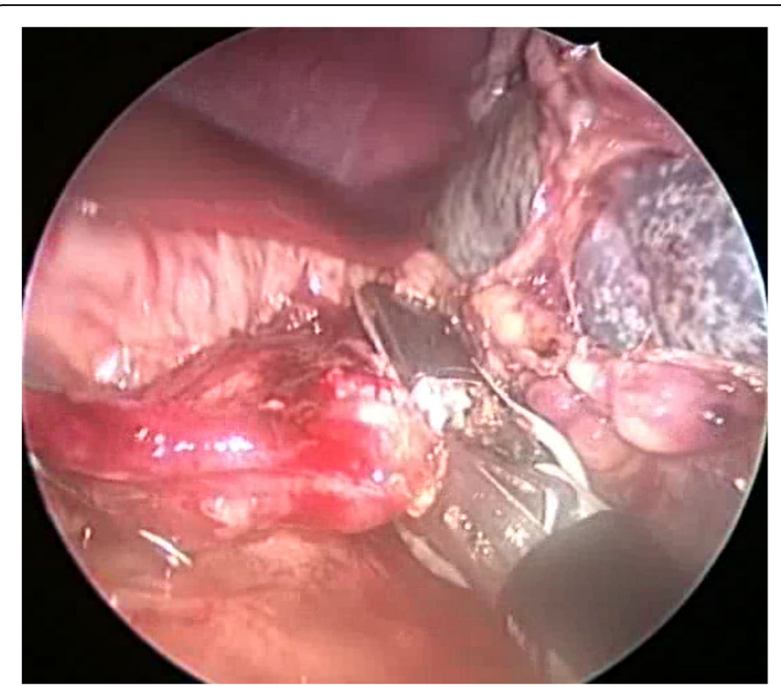

Fig. 2 The splenic vessels are then divided by ligasure

down by scissors. At the end, we confirm that the spleen is completely free and mobile. The spleen is positioned inside a 15 - or $10-\mathrm{cm}$ plastic bag, depending on the size of the spleen and the patient. The spleen is then removed by curved ring forceps, and the wounds are closed in layers.

\section{Results}

From January 2007 to June 2019, a total of 71 patients younger than 5 years with SCD underwent laparoscopic splenectomy (LS) at our hospital. There were 28 boys and 43 girls. The indications for splenectomy in our series included recurrent ASSC in 60 patients (85\%) and hypersplenism in 11 patients (15\%). The age at LS range from 2 to younger than 5 years (mean 3.2 years) and represent the study group. The mean operating time was $65 \mathrm{~min}$. All the cases were performed laparoscopically in this group of small size children. Preoperative ultrasound showed the size of the spleen on maximum length to range from 8 to $14 \mathrm{~cm}$ (mean $11 \mathrm{~cm}$ ). Some difficulties were encountered during surgery, particularly introducing the spleen in the plastic bag. We had 7 cases (9\%) detachment of the $15-\mathrm{cm}$ plastic bag from the metal ring while positioning the spleen. This was resolved by using a smaller plastic bag size of $10 \mathrm{~cm}$.

Thirty accessory spleens were identified in 25 patients (35\%) and were excised. None of our patients required blood transfusion intraoperatively.

Twelve patients (17\%) underwent a concomitant cholecystectomy because of concomitant gallstones. Patients with SCD usually stay in the hospital longer than other cases for splenectomy cases due to pain control, good hydration, and parent's satisfaction, in which in our series ranged from 2 to 4 days (median, 3 days). The mean follow-up was 86 months (range, 17 to 161 
months). We did not encounter any case of overwhelming postsplenectomy sepsis infection (OPSI) in our series.

Requirements of PRBC transfusion for our patients with SCD were found to be lower in the first year after LS compared to the 1 year prior to LS (about 60\% reduction). There were no postoperative complications reported. The cosmetic appearance was excellent.

\section{Discussion}

The presence of the spleen in children with sickle cell disease $(\mathrm{SCD})$ is a potential problem that may result in morbidity as well as mortality. These serious possible complications include acute vasoocclusive pain episodes, splenic sequestration crisis, stroke, splenic abscess, and splenic infarction. Acute splenic sequestration crisis (ASSC) is a major complication of SCD, and it is the most common cause of mortality in young children with SCD. It occurs when sickled erythrocytes get trapped in the spleen, resulting in the enlargement of the spleen with a rapid reduction in hemoglobin and abdominal pain [4]. The incidence of ASSC was found to occur in 10 to $30 \%$ of SCD children younger than 5 years $[5,6]$. The spleen in patients with SCD does not undergo fibrosis before the age of 5 years. Therefore, children younger than 5 years are at increased risk of ASSC [7]. The first episode of ASSC carries a high mortality rate, which may reach up to $12 \%$ [8]. Furthermore, the mortality of the recurrence of ASSC is even higher which maybe $20 \%$ [7]. Unfortunately, recurrence of ASSC is estimated to be $50 \%$ after the first episode [8]. Topley et al. [8] reported $30 \%$ of the patients with ASSC in his series developed hypersplenism which lead to the occurrence of splenomegaly, with subsequent thrombocytopenia and anemia.

The management of ASSC is still debatable in the literature [9]. The urgent management of ASSC is transfusion of blood products and crystalloid to restore blood volume. To avoid morbidity and fatal complications of ASSC, it is important to prevent its recurrence. Recurrence of ASSC is through medical management by repeated red blood cell transfusion protocol until splenectomy is performed [6]. In order to prevent recurrence of ASSC and hypersplenism, it is recommended to do early splenectomy in children with $\operatorname{SCD}[5,8,10]$.

To avoid the increased risk of overwhelming postsplenectomy infection (OPSI) reported in younger children, elective splenectomy is usually postponed until the child is older than 5 years $[9,11,12]$. Children who underwent splenectomy are at risk of OPSI which may occur in 5\% of patients and an incidence of $0.23-0.42 \%$ per year [13, 14]. However, the routine use of preoperative immunization against Streptococcus pneumoniae, Haemophilus influenzae, and Neisseria meningitides has decreased effectively the incidence of OPSI $[12,15,16]$. Yet, the actual incidence of OPSI remains to be established, because some patients may be missed and go unreported. The highest risk of OPSI was found to be within the first 2 years after splenectomy [17]. In comparison with adults, children younger than 5 years are at excess risk of more than 10\% [17]. The organisms responsible for OPSI include Streptococcus pneumoniae, Haemophilus influenzae, and Neisseria meningitidis. To avoid OPSI and reduce its occurrence, we immunize our patients preoperatively against Streptococcus pneumoniae, Haemophilus influenzae, and meningococcal vaccines. Postoperatively, we cover them with penicillin prophylaxis orally for 10 years. Prophylactic antibiotics postsplenectomy has been shown to be beneficial and recommended by many authors to reduce the incidence of OPSI [18].

Although there is an increased incidence of antibiotic resistance when used for a long time as well as the compliance which needs to be evaluated, we also educate the parents and instruct them to seek medical help in the presence of fever or infection. During the study period at our institution, no patient developed OPSI.

In the current years, it has been observed there is a great reduction in the incidence of OPSI, due to the routine use of preoperative immunization and prophylactic antibiotics [12]. Moreover, in children with SCD, they found in different reports that the incidence of sepsis is almost the same prior or after splenectomy $[19,20]$. Sorrells et al. reported 29 patients in whom splenectomy was done about 2 years of age, and they received preoperative vaccination and penicillin prophylaxis [21]. In this series, there was no difference in the incidence of sepsis pre- and postsplenectomy.

All children with SCD prior to auto infarction of the spleen have an impairment of phagocytic function and functional asplenia [22, 23]. Early splenectomy may be more beneficial than chronic blood transfusion in children with SCD [22, 23]. The advantages of long-term transfusion are of limited value because it does not restore splenic function $[6,24]$. In addition, chronic transfusion therapy does not prevent recurrent ASSC, and they will be at risk of recurrence [6, 24]. Nevertheless, long-term blood product transfusion has many disadvantages including blood transfusion reactions, risk of infections with immunodeficiency virus and hepatitis, alloimmunization, and iron overload [3, 25]. On the other hand, splenectomy will reduce blood transfusion requirements in children with SCD as well as prevent future sequestration episodes [7].

Currently, ASSC episodes and hypersplenism are considered the major indications for splenectomy in children with SCD [26, 27]. The treatment of ASSC and hypersplenism with anemia includes the restoration of 
circulating red cell mass and blood volume. In our series, like the others, we performed splenectomy when the patient developed two attacks of ASSC [28]. This is in an attempt to avoid the recurrence of the risk of ASSC of $40 \%$ and possible mortality rate of $20 \%[5,29]$.

Due to the variability of the size of the abdomen in relation to the age of these young children less than 5 years old, difficulties were encountered during the placement of the spleen inside the plastic bag in our patients. In our series, there were 7 cases $(9 \%)$ of separation of the $15-\mathrm{cm}$ plastic bag from the metal ring during positioning the spleen. A solution could be to assess the size of the abdomen in relation to the size of the spleen volume intraoperatively. Therefore, when operating on a small size abdomen and small spleen, it is reasonable to use a small plastic bag with a size of $10 \mathrm{~cm}$ to retrieve the spleen, instead of a size of $15 \mathrm{~cm}$. Furthermore, when dealing with a spleen size more than $10 \mathrm{~cm}$ in length, it is better to use a $15-\mathrm{cm}$ plastic bag and place the lower left port more caudal in the left groin for the introduction of the plastic bag and allow it to open easily.

We have chosen not to delay splenectomy till the patient reaches 5 years old when there is an indication for splenectomy, and the youngest in the series was 2 years old. In the present series, the indications for splenectomy were recurrent ASSC in 60 patients (85\%), followed by hypersplenism in 11 patients (15\%). None of our patients had a preoperative splenic abscess or massive splenic infarction which was reported by other series [26]. We found in our series that SCD patients with hypersplenism had a reduction in PRBC transfusion requirements with a good response to splenectomy. The number of units transfused decreased by about $60 \%$ in 1 year postsplenectomy.

\section{Conclusion}

Laparoscopic splenectomy in young children less than 5 years of age with sickle cell disease is a safe and effective treatment. When patients are given preoperative vaccination and penicillin prophylaxis, OPSI rarely occurs. There is no need to wait until the patient is older than 5 years to perform a splenectomy in patients with SCD, when there is an indication for splenectomy.

\section{Abbreviations}

LS: Laparoscopic splenectomy; SCD: Sickle cell disease; ASSC: Acute splenic sequestration crisis; OPSI: Overwhelming postsplenectomy infection; PRBC: Packed red blood cell

\section{Acknowledgements}

None

\section{Authors' contributions}

TA conceived the study and participated in its design. TA, RE, and WT participated in the acquisition, analysis, and interpretation of the data. RE and WT performed the critical revision.
TA drafted the work and was the major contributor in writing the manuscript and revised it. All authors read and approved the final manuscript.

\section{Funding}

None

\section{Availability of data and materials}

The datasets used and/or analyzed during the current study are available from the corresponding author on reasonable request.

\section{Ethics approval and consent to participate}

A written consent was taken before the operation in all cases. The study was approved through expedited review by the scientific/ethical committee of the Pediatric Surgery Department, King Abdullah Medical City, Maternity and Children's Hospital, Madinah, Kingdom of Saudi Arabia' with reference number 201.

\section{Consent for publication}

Patient identity did not appear in any part of the manuscript; therefore, consent for publication was not required.

\section{Competing interests}

The authors declare that they have no competing interests.

\section{Author details}

'King Abdullah Medical City, Maternity and Children's Hospital, Madinah, Kingdom of Saudi Arabia. ${ }^{2}$ Mansoura University, Mansoura, Egypt.

Received: 18 June 2020 Accepted: 1 September 2020

Published online: 12 November 2020

\section{References}

1. Tulman S, Holcomb GW III, Karamanoukian HL, Reynhout J. Laparoscopic splenectomy. J Pediatr Surg. 1993;28:689-92.

2. Hicks BA, Thompson WR, Rogers ZR, et al. Laparoscopic splenectomy in childhood hematologic disorders. J Laparoendosc Surg. 1996;6(Suppl 1): S31-4.

3. Wanko SO, Telen MJ. Transfusion management in sickle cell disease. Hematol Oncol Clin North Am. 2005:19:803-26 v-vi.

4. Lesher AP, Kalpatthi R, Glenna JB, Jackson SM, Hebra A. Outcome of splenectomy in children younger than 4 years with sickle cell disease. J Pediatr Surg. 2009:44:1134-8.

5. Emond AM, Collis R, Darvill D, et al. Acute splenic sequestration in homozygous sickle cell disease: natural history and management. J Pediatr. 1985;107:201-6.

6. Kinney TR, Ware RE, Schultz WH, et al. Long-term management of splenic sequestration in children with sickle cell disease. J Pediatr. 1990;117:194-9.

7. Haricharan RN, Roberts JM, Morgan TL, et al. Splenectomy reduces packed red cell transfusion requirement in children with sickle cell disease. J Pediatr Surg. 2008;43:1052-6.

8. Topley JM, Rogers DW, Stevens MCG, et al. Acute splenic sequestration and hypersplenism in the first five years in homozygous sickle cell disease. Arch Dis Child. 1981;56:765-9.

9. King H, Shumacker HB Jr. Splenic studies. Susceptibility to infection after splenectomy performed in infancy. Ann Surg. 1952;136:239-42.

10. Al Salem AH, Qaisaruddin S, Naserullah Z, et al. Splenectomy and acute splenic sequestration crises in sickle cell disease. Pediatr Surg Int. 1995;11: 26-228

11. Schwartz P, Sterioff S, Mucha P. Postsplenectomy sepsis and mortality in adults. JAMA. 1982;248:2279-83.

12. Jugenburg $M$, Haddock $G$, Freedman $M$. The morbidity and mortality of pediatric splenectomy: does prophylaxis make a difference? J Pediatr Surg. 1999;34:1064-7.

13. Bisharat N, Omari H, Lavi I, Raz R. Risk of infection and death among postsplenectomy patients. J Inf Secur. 2001;43:182-6

14. Castagnola $E$, Fioredda F. Prevention of life-threatening infections due to encapsulated bacteria in children with hyposplenia or asplenia: a brief review of current recommendations for practical purposes. Eur J Haematol. 2003;71:319-26 
15. Davies JM, Barnes R, Milligan D. Update of guidelines for the prevention and treatment of infection in patients with an absent or dysfunctional spleen. Clin Med. 2002;2:440-3.

16. Konradsen $\mathrm{HB}$, Henrichsen J. Pneumococcal infections in splenectomized children are preventable. Acta Paediatr Scand. 1991;80:423-7.

17. Weledji EP. Benefits and risks of splenectomy. Int J Surg. 2014;12:113-9.

18. Newland A, Provan D, Myint S. Preventing severe infection after splenectomy. BMJ. 2005;331:417-8.

19. Wright JG, Hambleton IR, Thomas PW, et al. Postsplenectomy course in homozygous sickle cell disease. J Pediatr. 1999;134:304-9.

20. Kalpatthi R, Kane S, Rackoff B, Disco D, Jackson S. Clinical events after surgical splenectomy in children with sickle cell anemia. Pediatr Surg Int. 2010;26:495-500.

21. Sorrells DL, Morrissey TB, Brown MF. Septic complications after splenectomy for sickle cell sequestration crisis. Pediatr Surg Int. 1998:13:100-3.

22. Adekile AD, Owunwanne A, Al-Za'abi K, et al. Temporal sequence of splenic dysfunction in sickle cell disease. Am J Hematol. 2002;69:23-7.

23. Pearson HA, Gallagher D, Chilcote R, et al. Developmental pattern of splenic dysfunction in sickle cell disorders. Pediatrics. 1985;76:392-7.

24. Rogers DW, Serjeant BE, Serjeant GR. Early rise in "pitted" red cell count as a guide to susceptibility to infection in childhood sickle cell anemia. Arch Dis Child. 1982:57:338-42.

25. Rao S, Gooden S. Splenic sequestration in sickle cell disease: role of transfusion therapy. Am J Pediatr Hematol Oncol. 1985;7:293-301.

26. Al-Salem AH. Indications and complications of splenectomy for children with sickle cell disease. J Pediatr Surg. 2006:41:1909-15.

27. Sounthararajah Y, Vichinsky E, Embury SH. Sickle cell disease. In: Hoffman R, Benz EJ, Shattil SJ, et al., editors. Hoffman: Hematology: basic principles and practice. 4th ed. Philadelphia: Churchill Livingstone (Elsevier); 2005. p. 605-34.

28. Emond AM, Morias $\mathrm{P}$, Venugobal $\mathrm{S}$. Role of splenectomy in homozygous sickle cell disease in childhood. Lancet. 1984:88-90.

29. Mills MI. Life threatening complications of sickle cell disease in children. JAMA. 1985:254:1487-91.

\section{Publisher's Note}

Springer Nature remains neutral with regard to jurisdictional claims in published maps and institutional affiliations.

\section{Submit your manuscript to a SpringerOpen ${ }^{\circ}$ journal and benefit from:}

- Convenient online submission

- Rigorous peer review

- Open access: articles freely available online

High visibility within the field

- Retaining the copyright to your article

Submit your next manuscript at $\boldsymbol{\nabla}$ springeropen.com 